\title{
Agile Data Architecture in Mining Industry for Continuously Business-IT Alignment: EA Perspective
}

\author{
Rika Yuliana ${ }^{1}$, Budi Rahardjo ${ }^{2}$ \\ ${ }^{1}$ Faculty of Science and Technology Ar-Raniry Islamic State University Banda Aceh, Aceh, Indonesia \\ School of Electrical Engineering and Informatics \\ ${ }^{2}$ Institut Teknologi Bandung Bandung, West Java, Indonesia \\ ${ }^{1}$ rika.yuliana03@gmail.com, ${ }^{2}$ rahard@gmail.com
}

\begin{abstract}
Data plays a vital role particularly in mining enterprises to foster innovation and business performance through precise decision-making. Scientists have created many kinds of database technology to support them, such as big data, data cloud, etc. Meanwhile business is always facing a fluctuant situation in using those various database technologies. Unfortunately, there is still hard to use database technology in a proper way because there are no model rules in making a perfect planning so that they can choose suitable tools for its own case. Therefore, this paper aims to design an agile enterprise data architecture model rules (blueprint) in mining company based on various frameworks, tools and methods/techniques so that managers can govern their data asset for sustainably business-IT alignment. This data architecture reference models can be easily adopted by CIOs in order to move toward an integrated mining enterprises as well as guide user in producing a precise decision-making.
\end{abstract}

Keywords—data architecture; reference model; agile; enterprise architecture; alignment

\section{INTRODUCTION}

Studies by Jenkins[1] inferred certainly that one of the largest chances miners had become to analyze from other industries and move closer to an integrated mining enterprise through the use of architecture benchmark. The mining industry has benefits that other industries did not have. It could leverage the 15 to 20 years maximum other industries spent in trying to apprehend after which move in the direction of an integrated enterprise. Through utilizing an integration model, communication and data standards that simplify integration, after which choosing and distributing solutions that suit with the parameters of their plans and the requirements chosen, they could acquire in a few years what other industries took a long time to perform.

Data is at the core of modern usefulness, highly sought and meticulously accrued after which left to sit in silos, misconceive and underutilized. A file reveals that there are various possibilities to be had for utilities as they start to specify the silos throughout their enterprise and join different information assets to make more thoroughly informed decisions. Meanwhile, data can force huge modifications, but simplest while it feeds the massive illustration. Therefore, references for requirements include the following:

- conceive what data your enterprise has these days and what it's doing with the data

- recreate what data is wanted to construct a complete picture of your company's belongings
- investigate how distinct data sources can be leveraged across your enterprise, as an example: how data asset affects areas including cyber-security and outage management

- think the character of customer data and social media in constructing a more comprehensive illustration of the application for each personnel and customers

- Plan for the way emerging technologies, which includes micro-grids and DERs, will suit to your enterprise in the name of data needs and possibilities, in addition to how those technologies may additionally modify your organization's method in the direction of data [2].

Enterprise-level data architectures guarantee that the disintegration of the integrated data store is minimized. This guarantees that latter-day work is sustainable whilst new development can be held. Additionally, utilizing the same model also ensures that a foundation gets along with the execution of new techniques and technologies. They locate tools and methods with regards to each other with the aid of distinctive feature of an engineered building. In addition they provide a way of quantifying risks and costing for or in opposition to enforcing a brand new aspect of the architecture. With a view to obtain the lofty goal of corporate or enterprise data architecture, it requires the organizational management in indicating data as the critical resource and asset as it is[3]. 
Given the challenges outlined above, the objectives of this paper are to (1) explore overall utility component of enterprise data architecture in mining industry by using various tools and techniques/methods; (2) make an integrated relationship between them as a standard for integration; (3) propose enterprise data architecture reference models for a better governance purposes in mining enterprises.

The core contribution of this paper is becoming a guidance for mining enterprise while generating an agile data architecture blueprint that integrates various data entity in accordance with data architecture principles and standards. Through agile data architecture, a user can easily govern the data asset so that can provide better communication among them for the precise decisionmaking process.

Agile enterprise architecture is claimed as one of the solutions for many industries in facing a meticulous problem when they use information and communication technology. The problem is changes. In order to fulfill business performance and innovation needs, many industries require an architecture that aligns with the capability of the industry, in this case, mining industry. Therefore we propose an enterprise architecture metamodel [4] by using TOGAF framework as the preliminary research to formulate the edge $( \pm 60 \%)$ and quality of model rules including various domains (business, application, data, technology) and perspectives (contextual, conceptual, logical and physical). Due to the limitation of time, however, it is required to continue the depth (perspectives) and breadth (domains) of the agile enterprise architecture. Regarding the issue, complete model rules of agile enterprise architecture remain to be developed such as agile business architecture[5], agile data architecture, and so on.

\section{RESEARCH METHOD}

There may be a crucial lesson for the architect nowadays: design is an outward-in process, not inwardout. All great architects start with humans and what they want from the system that is designed by architects. Due to the fact that agile architecture requires an enterprise point of view at the interactions among business and IT, it's vital for the architect on the way to set up business architect on the head, and take into account all the various models that the business is right to be applied for reflecting the capabilities in each of the business and the IT that serves it [6].

The method that data is used, shaped, and saved has improved to the matter that there may be exactly present an area of taking a look at that may be referred to as "data architecture." There are numerous aspects of data architecture due to the fact that, as we shall see, data is complicated. The 4 most thrilling aspects of data architecture are: (1) the physical manifestation of data; (2) the logical linkage of data; (3) the internal format of data, and (4) the file structure of data. Each of these factors of data has advanced interdependently through the years. Data architecture can best be explained in terms of the evolution of each of these aspects of data architecture. The evolution of data architecture is seen in Figure 1[7].

Metamodels are a central idea of Enterprise Architecture (EA), reflecting the basic artifacts of business and IT. These high extent models provide a general language and a clear view of the composition of and dependencies among relevant parts of the enterprise [8]. In quintessence, this is achieved by a way of supplying a template for models: the permissible entities and their connections prescribed via the metamodel, so that all models based totally upon it are coherent. In this way, the metamodel enforces semantic rigor between some of the models afterward created in its image. Such rigor is a precondition for a successful communication and documentation[9].

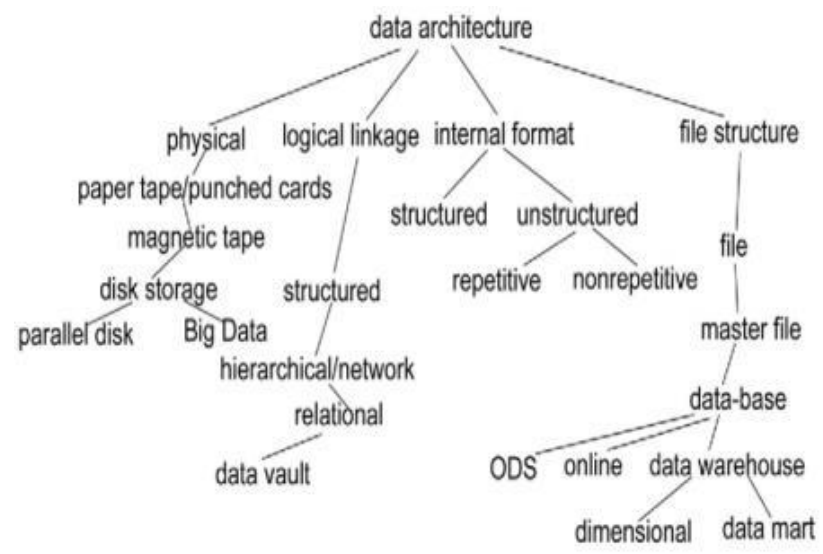

Figure. 1. The expansion of data architecture[7].

Studies suggested an incorporated solution of a data integration and decision support system for mines primarily based on a data warehouse. As data from more than one resources continue to be incorporated, both support and core processes in a value chain, start to divide a general information resource. Those new technologies create possibilities for mining more efficiently. Those inefficiencies will no longer handiest come from the extracted element, however from the entire value chain. Some of the recognized benefits of integration data include enhancing ore body reconciliation, automatic mine-mill integration, smart mine making plans, enhance production management, enhancements in planned maintenance, and inside the area of occupational health, most significantly, safety and risk management[10].

The metamodel should offer a basic model with the minimum characteristic set after which assist the inclusion of non-compulsory extensions in the course of engaged tailoring. The core metamodel affords a minimum set of architectural content to help traceability throughout artifacts. Additional metamodel ideas for guiding more particular or more in-depth modeling are contained within a set of extensions that logically assemble the extension of catalogs, matrices, and diagrams, even allowing concentrate on regions of particular interest and topic. The core content metamodel in data architecture is data entity[11]. Therefore we create a data architecture metamodel in Figure. 2 as an integrated solution for mining data architecture that consists of mining value 
chain, Togaf content metamodel and deliverables (artifacts).

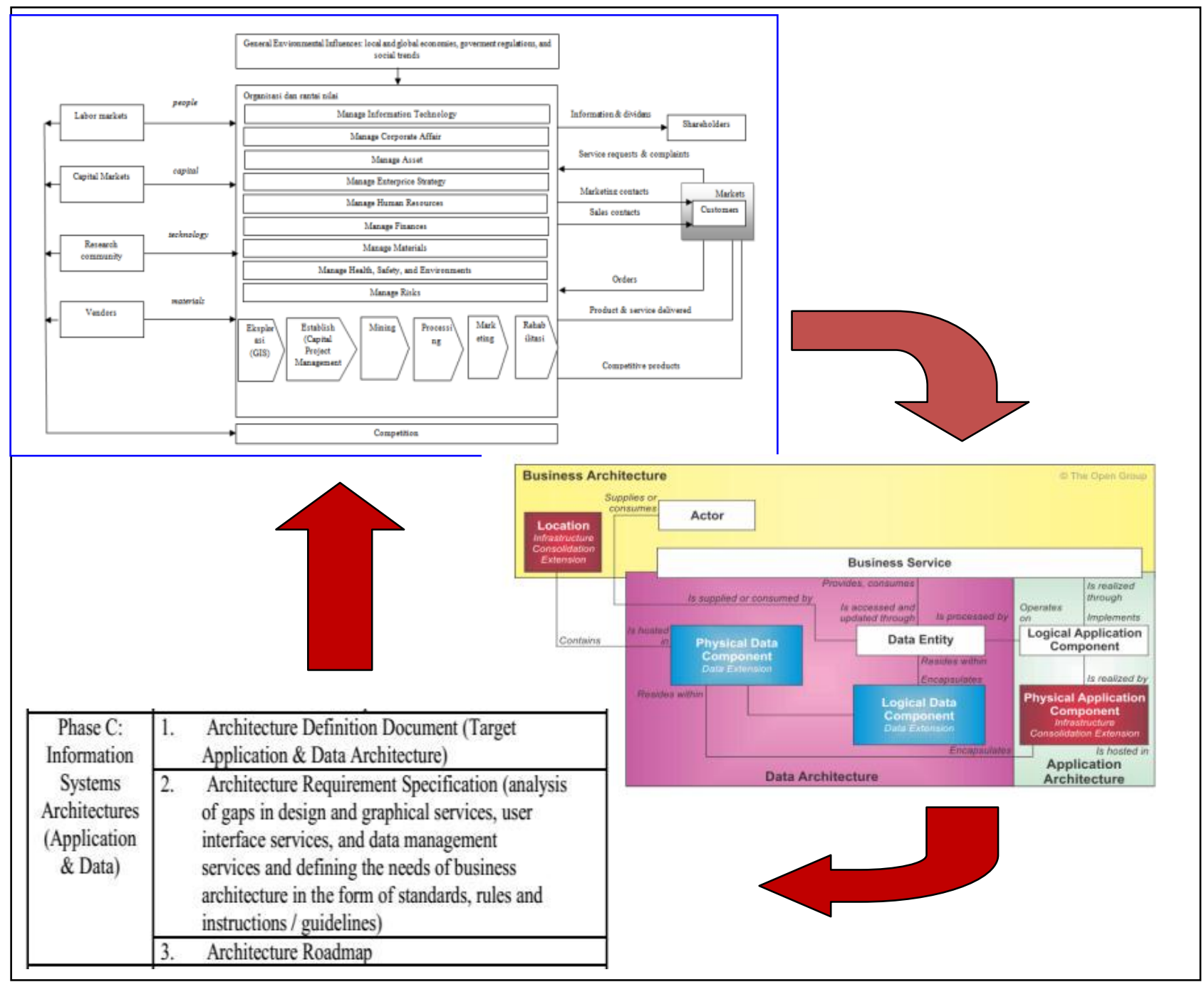

Figure. 2. Data architecture metamodel for mining enterprise.

\section{RESULT AND DISCUSSION}

\section{A. Deliverables of EnTERPrise Data ARChitecture IN MINING INDUSTRY}

Those artifacts that are resulted from techniques of the framework represent the inheritance of relatedness from data constituents in modern usage systems. Enterprise data architectures are the transcription of the information owner's product requirements from the proprietor's point of view. Latter-day data architectures are depending on the basis that data is living at the center of cutting-edge data processing. Data have to be approached from the highest level of perspective; since it is apprehended as the real-world objects that describe and exists as a characteristic of normal business operation[3]. Therefore, we generate data entities for data architecture in mining enterprise from real user requirements (business rules) that can be seen in Table I. This represents the main (file) structure of data architecture.
A Reference architecture catches the quintessence of the architecture in a set of systems. The aim of a Reference architecture is to offer direction for the improvement of architectures for new variations of the system or extended systems and product clusters. A Reference structure is created by taking pictures the essentials of present architectures and by taking into consideration future wishes and possibilities, starting from certain technology to patterns of business models and market segments[5].

B. Database Architecture for Mining Enterprise Data $\rightarrow$ Structured (Model in Every Level of Abstraction) \& Unstructured (Taxonomy)

In general, there are two types of data found in a corporate, structured data and unstructured data. Structured data is the data that has a predictable and systematically occurring format of data. Unstructured data, on the contrary, is unpredictable data and has no structure that is recognizable for a computer[7]. Therefore, structured data can be modeled into a further 
level of abstraction (conceptual, logical and physical) for can be classified into a taxonomy for various usage. data governance purposes. Meanwhile, unstructured data

TABle I. The Main (FILE) Structure of Data ARChitecture

\begin{tabular}{|c|c|c|c|}
\hline Applications & Descriptions or comments & Data Entity & Data Entity Type/ Category \\
\hline $\begin{array}{l}\text { All systems within the } \\
\text { company to manage geological } \\
\text { and mineralogical data; Such } \\
\text { as GIS (Geographic } \\
\text { Information System, etc.) }\end{array}$ & $\begin{array}{l}\text { Information systems that have the ability to build store, manage and } \\
\text { display geo-referenoed information, such as data identified by location, in } \\
\text { a database. }\end{array}$ & $\begin{array}{l}\text { The entities in the geographic databas a that is definadas an } \\
\text { object discrete / separate (eg, buildings, bridges, households, } \\
\text { businesses, etc.) or as an abstract object that is defined in } \\
\text { terms of space / space oocupied (for example, a piece ofland, } \\
\text { standing timber, wetlands, soil types, contours, etc.). }\end{array}$ & $\begin{array}{l}\text { - Geological index } \\
\text { - Geophysical Prospects (possibly land, air, } \\
\text { or both). } \\
\text { - Soil samples, geochemistry, wells, and trial } \\
\text { mines. } \\
\text { - Surface or underground. }\end{array}$ \\
\hline $\begin{array}{l}\text { Strategic Portfolio } \\
\text { Management Application }\end{array}$ & $\begin{array}{l}\text { Strategic Portfolio Management combines and delivers visibility into } \\
\text { financial, strategic, and operational aspects of project potfolios to } \\
\text { enforce governance, to makedecisions based on facts and to maximize } \\
\text { the return on existing as sets. }\end{array}$ & $\begin{array}{l}\text { List of things, processes, loctions, activities, goals and } \\
\text { organizational structure }\end{array}$ & $\begin{array}{l}\text { An important resource arrangement to determina } \\
\text { which projects will be contimued and which will } \\
\text { be corrected or canceled. }\end{array}$ \\
\hline $\begin{array}{l}\text { Capital investment } \\
\text { management \& } \\
\text { decommissioning Application }\end{array}$ & $\begin{array}{l}\text { The devalopment and construction of new mines andproces sing plants is } \\
\text { a very intensive / capital intensive project }\end{array}$ & $\begin{array}{l}\text { The final Mining Layout Design includes all mining techrical } \\
\text { inputs (egvertilation and stone engineering). }\end{array}$ & $\begin{array}{l}\text { All master data required to perfom device } \\
\text { maintenance effectively, including device } \\
\text { master notes, Maintenance Plan, Point size, Task } \\
\text { List, Bill of Materials (BOMs) etc. }\end{array}$ \\
\hline Mine planning \& scheduling & $\begin{array}{l}\text { The mine planning provides informationabout the blocks to bemined } \\
\text { and the expected ore grades. The optimal sequence of blocks to bemined } \\
\text { is determined. This process is usually carried out in a third-party system. } \\
\text { The results of theplarning process (tormage and grade) will then be used } \\
\text { in subsequart production planning. }\end{array}$ & $\begin{array}{l}\text { - Quality and quartity peramaters (egkg, ounces, } \% \text { of } \\
\text { liquid, \% of wasta, } \% \text { of cortaminants, etc) } \\
\text { production costs, sales, andmarketing infomation such } \\
\text { as price, demand, and risk parameters }\end{array}$ & $\begin{array}{l}\text { blocks of mineral resourceinventory where they } \\
\text { mine (blockpay) and in which order (depending } \\
\text { on practical design criteria) }\end{array}$ \\
\hline $\begin{array}{l}\text { Production performance } \\
\text { management }\end{array}$ & $\begin{array}{l}\text { Once the production plan has been determined, actual production } \\
\text { (tonnage and grade) is captured into a production sequence. In addition, } \\
\text { this production order is used to accumulate all costs. Production } \\
\text { executions also require integration of historical data and real-time } \\
\text { systems. }\end{array}$ & $\begin{array}{l}\text { BOM_BILL_OF_MATERIALS } \\
\text { BOM_OPERATIONAL_ROUTINGS } \\
\text { INVENTORY_ITEM }\end{array}$ & Bills of basic materials androutes \\
\hline Demand Planning & $\begin{array}{l}\text { Demand Planning is us ed to make market demand forecasts of a } \\
\text { company's products. The estimates are based on customer contracts, } \\
\text { planned sales orders and other demands (eg between companies) }\end{array}$ & Item, order, custome, departmant, etc & $\begin{array}{l}\text { Products, Bill of Materials, Customers, } \\
\text { Organization etc. }\end{array}$ \\
\hline $\begin{array}{l}\text { Sustainable envirormental \& } \\
\text { rehabilitation design } \\
\text { application }\end{array}$ & $\begin{array}{l}\text { Systems that can evaluste the envirormental properties of buildings, in } \\
\text { order to assess potential environmertal inmprovemerts. }\end{array}$ & $\begin{array}{l}\text { The architectural model governs the location within the } \\
\text { building, the surfacelavels (wall, base, roof) and surface } \\
\text { elements. } \\
\text { Integration of environmertal data (s clarpower data, Energy } \\
\text { data, sonic data, and Patrimonial \& visibility data) }\end{array}$ & $\begin{array}{l}\text { This systemprovides a rapresentation of the } \\
\text { entities that makeup the building, and } \\
\text { environment related data (solar power data, } \\
\text { energy and sonic sourcedata, the data } \\
\text { architecture, etc.) }\end{array}$ \\
\hline
\end{tabular}

Conceptual design is the initial stage in the database design process. The objective at this stage is to design a database that is independent of database software and physical details (levels of abstraction). The product of this process is a conceptual data model that describes the main data entities, attributes, relationships, and constraints of a given problem domain. This design is descriptive and narrative in form. In other words, it is commonly composed of a graphical representation as well as textual descriptions of the main data elements, relationships, and constraints[12]. In this case, we take one sample of data entity for one application area of mining enterprise, for instance, demand planning application as can be seen in Figure 3.

Logical design is a secondary stage in the design phase that matches the conceptual design to the specific constructs of the selected DBMS and is therefore software-dependent. Logical design is applied to translate the conceptual design into the internal model for a chosen database management systems, such as DB2, SQL Server, Oracle, IMS, Informix, Access, or Ingress[12]. In this case, we assume that this logical model can be matched for any kind of DBMS chosen. Therefore, this logical model has to be adjusted for each specific mining enterprise application (e.g., demand planning application) as can be seen in Figure 4.

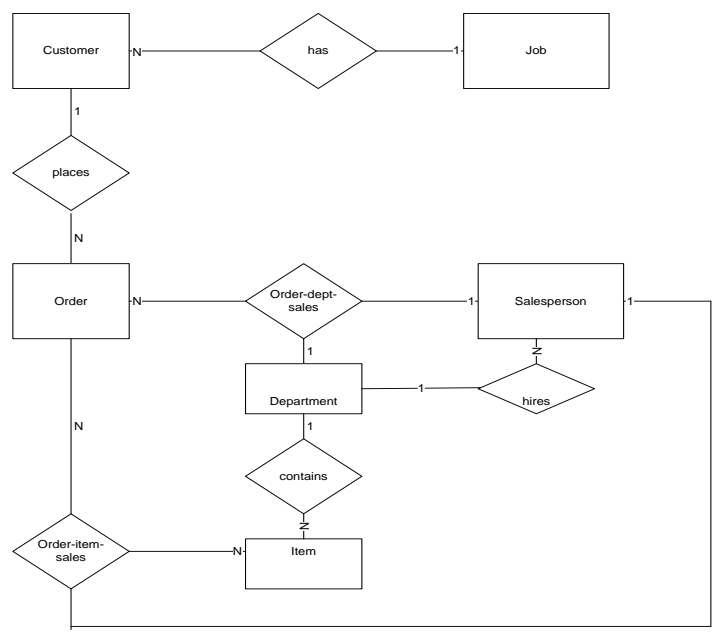

Figure. 3. Conceptual data model diagram for the ER model in demand planning application[13]. 


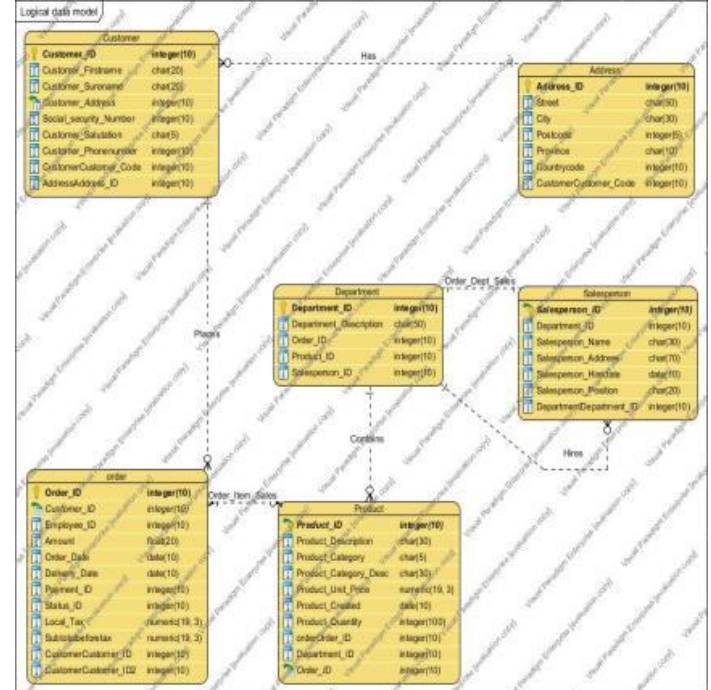

Figure 4. The logical data model in demand planning application.

Physical design is a final stage of database design that maps the data storage and access characteristics of a database to ensure its integrity, security, and performance. Since these characteristics are a function of the types of devices supported by the hardware, the data access methods supported by the system of physical design are both hardware- and softwaredependent. Physical design can serve a very technical job that affects not only the accessibility of the data in the storage device(s) but also the performance of the system[12]. Physical design is the lowest level in structured data architecture. It can be seen in Figure 5.

\section{A. Data Management Services}

In designing data management services, we combine the TOGAF framework with DMBOK as can be seen in Table II. According to the DMBOK[14], data management is the business function that develops and executes plans, policies, practices, and projects that acquire, control, protect, deliver, and enhance the value of data and information. In some cases, data management is a synonym of a data management functions in the enterprise that performs data management activities. In other words, TOGAF architecture provides the "what" things, meanwhile DMBOK data governance contributes in "how" things.

\section{B. Roadmap (Goal Summary)}

Architecture roadmap registers individual work packages that will realize the target architecture and lays them out on a timeline to show the progression from the baseline architecture to the target architecture. Architecture roadmap is composed of the project list, time-oriented migration plan, and implementation recommendations. According to Togaf data architecture concept, a data roadmap is needed to prioritize activities over the coming phases. The initial data architecture roadmap will be used as raw material to assist more detailed definition of a consolidated, cross-discipline roadmap within the opportunities and solutions phase[11]. In this case, data architecture roadmap is seen as one unit with other architecture domain. For more detailed about data architecture roadmap can be seen at Thesis in Appendix G Transition Architecture Document[15].

At the end of the research, we evaluated the proposed model in order to measure the accuracy of the results. Peffers said that there are many ways to observe and measure how well the artifacts supports a solution to the problem, such as satisfaction surveys, client feedback, simulations, and so on[16]. Thus, we took client feedback (expert judgment) from the mining enterprise where the research went on. They claimed that this model rules solved their problem. However, these results have to be continued through design iteration process simultaneously in the future.

\section{CONCLUSION}

In this paper, we proposed an agile data architecture for mining enterprise based on a various frameworks, tools and methods/techniques in order to guide the user in generating a data architecture blueprint that can produce a precise decision-making. In accordance with data architecture standards, and principles, mining enterprise data entity has a unique model depends on its own value chain. Those data entities are then explored into each level of abstraction for integration purposes. Data management services provide many functions for governing data architecture artifacts. Data architecture roadmap can give information for future agile data architecture development.

\section{REFERENCES}

[1] J. Jenkins, Bounding ahead: IT maturity takes the mining industry from laggard to leader. 2015.

[2] ABB Research Survey, The data core driving utility operational excellence through data integration. USA, 2016.

[3] C. Tupper, Data Architecture, "From zen to reality.” MA, USA: Elsevier, 2011.

[4] R. Yuliana and B. Rahardjo, "Designing an agile enterprise architecture for mining company by using TOGAF framework," in 4th International Conference on Cyber and IT Service Management, 2016.

[5] R. Yuliana and B. Rahardjo, "Designing business architecture reference model for the mining industry by using TOGAF framework," in International Conference on Quality in Research, 2015.

[6] J. Bloomberg, The Agile Architecture Revolution: How Cloud Computing, RESTBased SOA, and Mobile Computing Are Changing Enterprise IT. Hoboken, New Jersey: John Wiley \& Sons, 2013.

[7] W. H. Inmon and Linstedt, Data Architecture: A Primer for the Data Scientist. USA: Elsevier, 2015.

[8] S. Aier, S. Kurpjuweit, J. Saat, and R. Winter, "Enterprise Architecture Design as an Engineering Discipline," vol. 1, pp. 36-43, 2009.

[9] J. Saat, U. Franke, R. Lagerström, and M. 
Ekstedt, "Enterprise Architecture Meta Models for IT / Business Alignment Situations."

[10] X. Li and S. Zhong, "Data integration based on mining value chain," in International Conference on E-Product, E-Services and EEntertainment (ICEEE), 2010.

[11] "The Open Group," 2011. [Online]. Available: http://pubs.opengroup.org/architecture/chap10.

[12] C. C. and S. Morris, Database systems: design, implementation, and management. USA:

Cengage Learning, 2015.

[13] M. Vogt and Kieth Hales, "Strategic Alignment of ICT Projects with Community Values in Local Government," in 43rd Hawaii International Conference on System Sciences,
2010.

[14] J. Ladley, Data governance: how to design, deploy, and sustain an effective data governance program. USA: Elsevier, 2012.

[15] R. Yuliana, "Designing enterprise architecture for the mining industry by using Togaf framework," Institut Teknologi Bandung, 2011.

[16] K. Peffers, T. Tuunanen, M. Rothenberger, and S. Chatterjee, "A design science research methodology for information systems research," Manag. Inf. Syst., vol. 24, no. 3, pp. 45-77, 2007.

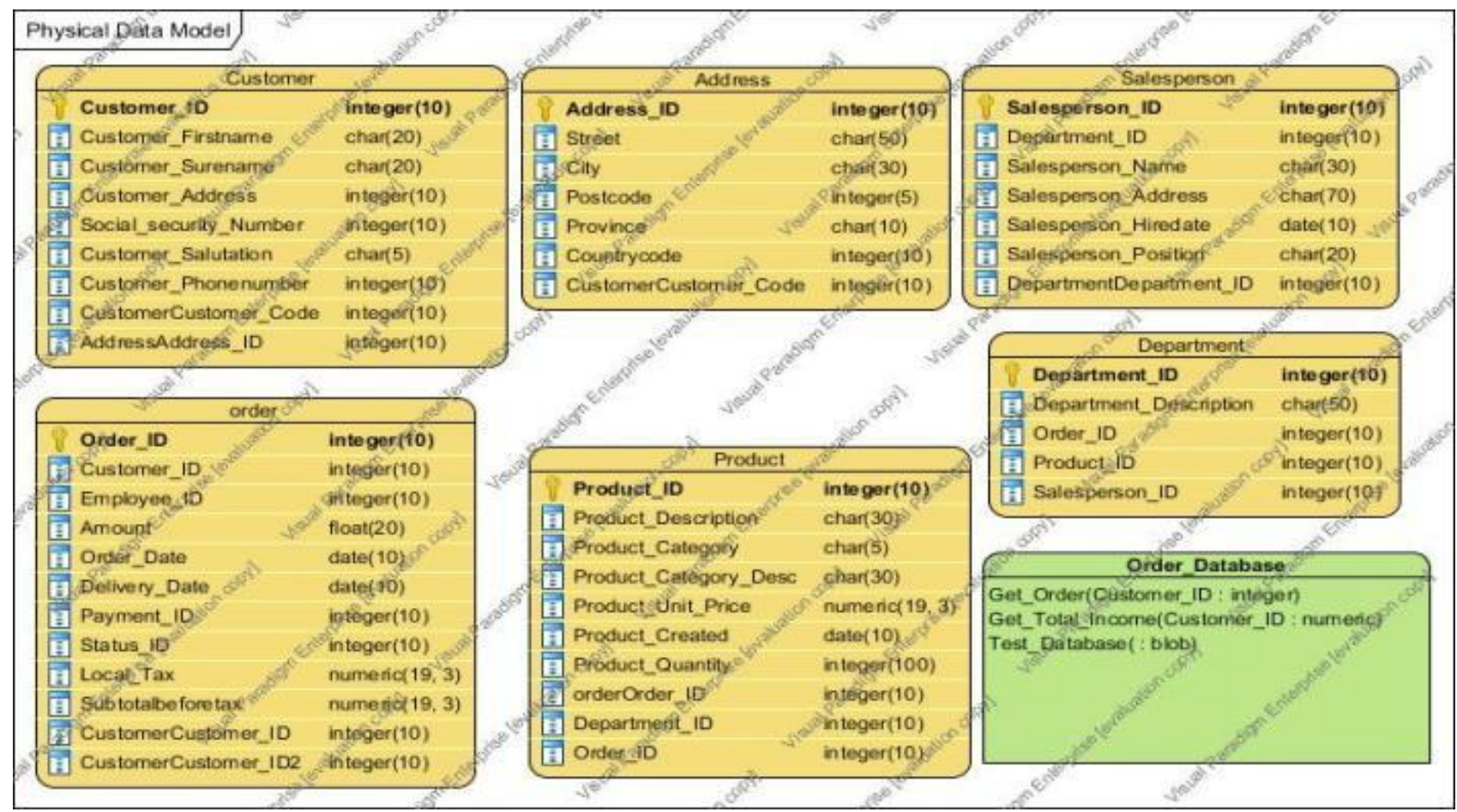

Figure 5. The physical data model in demand planning application. 
Table 2. DataManagement Services Matrix

\begin{tabular}{|c|c|c|c|c|c|c|c|c|c|c|}
\hline 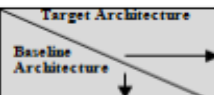 & $\begin{array}{l}\text { Data } \\
\text { dictionary/ } \\
\text { repository } \\
\text { service }\end{array}$ & 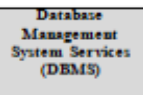 & 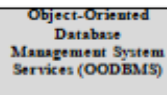 & $\begin{array}{l}\text { File } \\
\text { mangemeat } \\
\text { survices }\end{array}$ & $\begin{array}{l}\text { Qvery } \\
\text { procensing } \\
\text { functioum }\end{array}$ & $\begin{array}{l}\text { The dipplay } \\
\text { gemeration } \\
\text { function }\end{array}$ & $\begin{array}{c}\text { Report } \\
\text { seperation } \\
\text { function }\end{array}$ & $\begin{array}{l}\text { Network } \\
\text { function / } \\
\text { cencurreat } \\
\text { acteess }\end{array}$ & $\begin{array}{l}\text { Warcebouring } \\
\text { function }\end{array}$ & $\downarrow$ \\
\hline 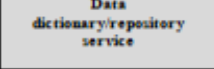 & & & & & & & & & & \\
\hline \begin{tabular}{|l} 
Datrabars Mrangement \\
Syytem Services (DBMMS)
\end{tabular} & & $\begin{array}{l}\text { Data sos bocans } \\
\text { where in is seeded }\end{array}$ & & & & & & & & \\
\hline 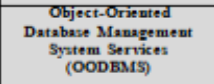 & & & & & & & & & & \\
\hline The mangerment urtikes & & & & 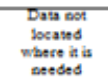 & & & & & & \\
\hline $\begin{array}{l}\text { Query processing } \\
\text { functions }\end{array}$ & & & & & 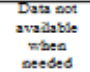 & & & & & \\
\hline $\begin{array}{l}\text { The dipplay goverstion } \\
\text { function }\end{array}$ & & & & & & 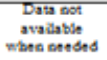 & & & & \\
\hline $\begin{array}{l}\text { Repert geperation } \\
\text { fuction }\end{array}$ & & & & & & & $\begin{array}{l}\text { Data } \\
\text { selasiouship } \\
\text { gaps }\end{array}$ & & & \\
\hline 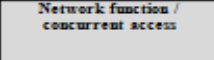 & & & & & & & & $\begin{array}{c}\text { Data } \\
\text { selisisanhip } \\
\text { Bap }\end{array}$ & & \\
\hline Warebouring function & & & & & & & & & $\begin{array}{l}\text { Data } \\
\text { restationatip gap }\end{array}$ & \\
\hline Ne & New & & New & & & & & & & \\
\hline
\end{tabular}

